\title{
Moisture Distribution and Structural Properties of Frozen Cooked Noodles with $\mathrm{NaCl}$ and Kansui
}

\author{
Jiarong Wang, Yangyue Ding, Mingyang Wang, Tianqi Cui, Zeyu Peng and Jianjun Cheng * \\ Grain Engineering Research Laboratory (10), College of Food Science, Northeast Agricultural University, \\ Harbin 150030, China; wjrsci@163.com (J.W.); dingyangyue77@163.com (Y.D.); \\ wmy15663028822@163.com (M.W.); cuitianqi0906@163.com (T.C.); zerypaul@163.com (Z.P.) \\ * Correspondence: jjcheng@neau.edu.cn; Tel.: +86-136-3364-0828
}

Citation: Wang, J.; Ding, Y.; Wang, M.; Cui, T.; Peng, Z.; Cheng, J. Moisture Distribution and Structural Properties of Frozen Cooked Noodles with $\mathrm{NaCl}$ and Kansui. Foods 2021, 10, 3132. https://doi.org/10.3390/ foods10123132

Academic Editor: Maria

Papageorgiou

Received: 11 November 2021

Accepted: 15 December 2021

Published: 17 December 2021

Publisher's Note: MDPI stays neutral with regard to jurisdictional claims in published maps and institutional affiliations.

Copyright: (c) 2021 by the authors. Licensee MDPI, Basel, Switzerland. This article is an open access article distributed under the terms and conditions of the Creative Commons Attribution (CC BY) license (https:/ / creativecommons.org/licenses/by/ $4.0 /)$.

\begin{abstract}
The effects of $\mathrm{NaCl}(1-3 \%)$ and kansui (0.5-1.5\%) on the quality of frozen cooked noodles (FCNs) were investigated, which provided a reference for alleviating the quality deterioration of FCNs. Textural testing illustrated that the optimal tensile properties were observed in $2 \% \mathrm{NaCl}$ $(\mathrm{N}-2)$ and the maximum hardness and chewiness were reached at $1 \%$ kansui $(\mathrm{K}-1)$. Compared to $\mathrm{NaCl}$, the water absorption and cooking loss of recooked FCNs increased significantly with increasing kansui levels $(p<0.05)$. Rheological results confirmed $\mathrm{NaCl}$ and kansui improved the resistance to deformation and recovery ability of thawed dough; K-1 especially had the highest dough strength. SEM showed N-2 induced a more elongated fibrous protein network that contributed to the extensibility, while excessive levels of kansui formed a deformed membrane-like gluten network that increased the solid loss. Moisture analysis revealed that N-2 reduced the free water content, while $\mathrm{K}-1$ had the lowest freezable water content and highest binding capacity for deeply adsorbed water. The N-2 and K-1 induced more ordered protein secondary structures with stronger intermolecular disulfide bonds, which were maximally improved in $\mathrm{K}-1$. This study provides more comprehensive theories for the strengthening effect of $\mathrm{NaCl}$ and kansui on $\mathrm{FCNs}$ quality.
\end{abstract}

Keywords: frozen cooked noodles; $\mathrm{NaCl}$; kansui; moisture distribution; structure; rheology; quality

\section{Introduction}

Frozen cooked noodles (FCNs), as a new type of instant noodle product, have grown increasingly popular among consumers due to their advantages in preservation, safety, and convenience, and now account for approximately $45 \%$ of the total noodle production $[1,2]$. However, freezing might reduce hardness, tensile force, aroma, and consumer acceptance of noodles [3]. These negative changes are closely related to the uneven water redistribution in the noodle matrix upon freezing and ice recrystallization caused by temperature fluctuations, which could lead to the loss of gluten network integrity and denseness, with implications for the machinability and rheological properties of the dough [4]. Currently, numerous studies emphasized the minimization of freeze-induced structural damage and quality deterioration during FCNs freezing.

Salts have been widely used as dough conditioners or quality improvers to improve the flavor, texture, and cooking characteristics of noodles. Depending on the types of salt in the recipe, the noodles are divided into two different types: white salted noodles containing $\mathrm{NaCl}$ and yellow alkaline noodles with $\mathrm{Na}_{2} \mathrm{CO}_{3}$ or $\mathrm{K}_{2} \mathrm{CO}_{3}$, or a mixture of them, called kansui [5]. Fu (2008) reported that the typical addition of salt was 1-3\% by flour weight, while approximately $0.5-1.5 \%$ of alkaline salts was used to make alkaline noodles [6]. $\mathrm{NaCl}$ could increase the mixing tolerance of the dough, extend the dough development time, and improve the dough sheeting properties and noodle quality by increasing the density of gluten network [7-9]. The alkaline salt contributed to the unique color, texture, and flavor of the noodles and promoted a denser gluten structure by strengthening the disulfide bonds and non-disulfide bonds cross-linking [10-12]. In spite of the addition of $\mathrm{NaCl}$ and 
kansui being a convenient and cost-effective means of improving the noodles quality, few studies have investigated their effects on frozen cooked noodles.

The deterioration process of FCNs quality is strongly dependent on the quantity, physical state, and location of the water [2]. Previous studies demonstrated that the sodium and chloride ions in the $\mathrm{NaCl}$ are dispersed around the proteins and act to retain the water. $\mathrm{NaCl}$ also accelerates the absorption of water into the flour and distributes it uniformly [8]. In addition, Li et al. (2017) revealed that alkali enhanced the interaction between aqueous and non-aqueous components [11]. However, most studies about $\mathrm{NaCl}$ and kansui focused on the interactions between them and fresh dough $[8,13]$. Few quantitative studies have focused on the effects of $\mathrm{NaCl}$ and kansui on frozen noodles, and even fewer studies have taken the water molecules movement into account.

The singularity of this work was to investigate the effect of different levels of $\mathrm{NaCl}$ $(1-3 \%)$ and kansui $(0.5-1.5 \%)$ on the quality of FCNs, and to elucidate the potential mechanisms for the transformation of noodle quality in terms of rheological behavior, microscopic morphology, water distribution, and protein structure of the dough. This study might provide a more comprehensive theoretical basis for broadening the applications of $\mathrm{NaCl}$ and kansui in the noodle industry.

\section{Materials and Methods}

\subsection{Materials}

Wheat flour (9.80\% moisture, $0.67 \%$ ash, and $11.75 \%$ protein) was obtained from Jinshahe Flour Industry Co., Ltd. (Xingtai, Hebei, China). Sodium chloride, sodium carbonate, and potassium carbonate were provided by Tianli Chemical Reagent Co., Ltd. (Tianjin, China). All reagents were analytical grade.

\subsection{Preparation and Sampling of FCNs}

The formulation of FCNs was composed of $200 \mathrm{~g}$ wheat flour, $70 \mathrm{~g}$ distilled water, and different levels of $\mathrm{NaCl}$ or kansui $(\%, w / w)$. The predetermined amount of $\mathrm{NaCl}$ or kansui was dissolved in water before adding. $\mathrm{NaCl}$ was added at $1 \%, 2 \%$, and $3 \%$ levels; kansui (a 9:1 mixture of sodium and potassium carbonate) was added at $0.5 \%, 1 \%$, and $1.5 \%$ levels; and the samples were named $\mathrm{N}-1, \mathrm{~N}-2, \mathrm{~N}-3, \mathrm{~K}-0.5, \mathrm{~K}-1$, and $\mathrm{K}-1.5$, respectively. The noodle without $\mathrm{NaCl}$ or kansui was the control.

The crumbly dough was obtained using an automatic dough mixer (M6-L30, Joyoung, Co., Ltd., Beijing, China) to knead for $5 \mathrm{~min}$. The dough was rested at $23^{\circ} \mathrm{C}$ for $30 \mathrm{~min}$. Subsequently, the dough was placed on a semiautomatic sheeting machine (Juxin Machinery Co., Ltd., Zaoyang, China) and the sheeting gaps were reduced to $1 \mathrm{~mm}$ gradually to obtain dough sheets. The resultant dough sheets were cut into noodle strands $(2 \mathrm{~mm}$ in width and $1 \mathrm{~mm}$ in thickness) with a cutter. Fresh noodles (30 g/500 mL water) were boiled for $3.5 \mathrm{~min}$ (optimal cooking time), and then immersed in $500 \mathrm{~mL}$ cold water $\left(4^{\circ} \mathrm{C}\right)$ for $1 \mathrm{~min}$. These noodles were drained for $1 \mathrm{~min}$ and placed in sealed bags. Then, they were frozen in an ultra-low temperature freezer (DW-HL100, MELNG, Hefei, China), with air temperature in convection at $-40{ }^{\circ} \mathrm{C}$, until the core temperature dropped to $-18{ }^{\circ} \mathrm{C}(\sim 60 \mathrm{~min})$. After freezing, the FCNs were stored at $-18 \pm 2{ }^{\circ} \mathrm{C}$ in the freezer (BCD-480WDGB, Haier Co., Ltd., Qingdao, China) for more than $24 \mathrm{~h}$ until use. Additionally, some fresh dough sheets were cut into $35 \mathrm{~mm}$ diameter discs and placed in polyethylene bags and frozen in the same procedure for further rheology testing [14].

\subsection{Rheological Properties Tests}

After fixed-time frozen storage, the dough sheets were removed from the polyethylene bags and put in a stainless-steel tray. Then, they were thawed in a constant temperature incubator at $25{ }^{\circ} \mathrm{C}$ and $75 \%$ relative humidity for $1 \mathrm{~h}$. Then, the rheology performance of doughs ( $\sim 3 \mathrm{~g})$ was determined by a Haake Mars 40 rheometer (Thermo Fisher Scientific, Waltham, MA, USA) following the method of Zhang et al. (2018) and equipped with a $35 \mathrm{~mm}$ parallel plate geometry at a gap of $1 \mathrm{~mm}$ [15]. 


\subsubsection{Dynamic Frequency Sweep}

A frequency sweep was run from $0.1-100 \mathrm{rad} / \mathrm{s}$ at a strain of $0.2 \%$ (within the linear viscoelastic region) and a temperature of $25 \pm 0.1^{\circ} \mathrm{C}$ to determine the storage modulus $\left(G^{\prime}\right)$, loss modulus $\left(G^{\prime \prime}\right)$ and $\tan \delta\left(G^{\prime \prime} / G^{\prime}\right)$ as functions of frequency [16]. The degree of dependence of $G^{\prime}$ on the frequency sweep $\left(z^{\prime}\right)$ and the strength of the dough $(\mathrm{K})$ was obtained by fitting the curves to the following the power-law model (Equation (1)):

$$
\mathrm{G}^{\prime}=\mathrm{K} \omega^{\mathrm{z}^{\prime}},
$$

where $\omega$ is the angular frequency.

\subsubsection{Creep Recovery Measurement}

At $25{ }^{\circ} \mathrm{C}$, within the linear viscoelastic range of the doughs $(0.2 \%$ strain), instant stress (250 Pa) was applied and maintained for $300 \mathrm{~s}$, and then stress was released to allow sample recovery for the next $300 \mathrm{~s}$. The experimental parameters were obtained by analyzing the creep and recovery curves using Haake RheoWin 4.83.0004 software (Thermo Fisher Scientific, Waltham, MA, USA), including maximum creep compliance $\left(\mathrm{J}_{\max }\right)$, zero shear viscosity $\left(\eta_{0}\right)$, relative elastic part of the maximum creep compliance $\left(\mathrm{J}_{\mathrm{e}} / \mathrm{J}_{\max }\right)$, and the relative viscous part of the maximum creep compliance $\left(\mathrm{J}_{\mathrm{v}} / \mathrm{J}_{\max }\right)$.

\subsection{Scanning Electron Microscope (SEM)}

The cross-sections of the frozen-dried FCNs were examined using a scanning electron microscope (Hitachi S-3400N) at 500 $\times$ magnification. The accelerating voltage for scanning was $5 \mathrm{kV}$ [17].

\subsection{Freezable Water Content}

The freezable water (FW) content was measured by differential scanning calorimeter (DSC 3, Mettler Toledo, Basel, Switzerland) referring to the method described by Hong et al. (2021) [14]. A sliced subsample of $\sim 10 \mathrm{mg}$ from each sample was placed into the DSC pan. Then, the pan was hermetically sealed. During the test, samples were held at $-40{ }^{\circ} \mathrm{C}$ for $10 \mathrm{~min}$ for the equilibrium of temperature and then heated from $-40{ }^{\circ} \mathrm{C}$ to $40^{\circ} \mathrm{C}$ at $10^{\circ} \mathrm{C} / \mathrm{min}$. Nitrogen was used as a carrier gas at a flow rate of $20 \mathrm{~mL} / \mathrm{min}$. The FW content (FW\%) was calculated by the following formula.

$$
\mathrm{FW} \%=\frac{\Delta \mathrm{H}_{\mathrm{W}}}{\Delta \mathrm{H}_{\mathrm{i}} \times \mathrm{TW}} \times 100 \%
$$

$\Delta \mathrm{H}_{\mathrm{W}}$, melting enthalpy, $\mathrm{J} / \mathrm{g}$ of water. $\Delta \mathrm{H}_{\mathrm{i}}$, the latent heat of the ice fusion, $334.3 \mathrm{~J} / \mathrm{g}$. TW, the moisture content of the sample, $g / g$.

\subsection{Measurement of Protons Migration and Distribution}

The water distribution was determined using a $23-\mathrm{MHz}{ }^{1} \mathrm{H}$ low-field nuclear magnetic resonance analyzer (LF-NMR, MesoMR23-060H-I, Suzhou Niumag Electronic Technology Co., Ltd., Suzhou, China) equipped with standard micro imaging accessories. The recooked FCNs (2.50 g) were weighed accurately and sealed in PET/PE bags to avoid the interference of air and moisture [4].

For the LF-NMR test, the transverse relaxation curves were acquired using the CarrPurcell-Meiboom-Gill pulse sequence. The parameters employed are as follows: echo time $(\mathrm{TE})=0.2 \mathrm{~ms}$, the number of echoes $(\mathrm{NECH})=10,000$, the interval time of sampling $(\mathrm{TW})=2500 \mathrm{~ms}$, and the number of scans $(\mathrm{NS})=2$.

The water migration of FCNs was observed using magnetic resonance imaging (MRI). A 15-mm radiofrequency (RF) coil was selected and a standard SPIN-ECHO (SE) sequence was used to produce images. The parameters were: $\mathrm{TE}=20 \mathrm{~ms}$, TR $=500 \mathrm{~ms}$, and Averages $=3$. 


\subsection{Attenuated Total Reflectance-Fourier Transform Infrared Spectroscopy (ATR-FTIR) Analysis}

The molecular interactions of freeze-dried dough were analyzed using ATR-FTIR (Nicolet iS50, Thermo Fisher, Waltham, MA, USA) according to the method of Ying et al. (2019) [18]. The spectra were generated in absorption mode in mid-IR (ca. 4000-525 cm ${ }^{-1}$ ) at a resolution of $4 \mathrm{~cm}^{-1}$ in 64 scans. The positions of the absorbance peaks located in the amide I region were determined using Fourier self-deconvolution and the second derivative using Peak Fit software (version 4.12). The peaks in the range $1650-1660 \mathrm{~cm}^{-1}$ corresponded to $\alpha$-helix, $1660-1700 \mathrm{~cm}^{-1}$ and $1610-1640 \mathrm{~cm}^{-1}$ represented $\beta$-turn and $\beta$-sheet, respectively, and $1640-1650 \mathrm{~cm}^{-1}$ indicated the random coil.

\subsection{Measurement of Free Sulfhydryl Content}

The content of the free sulfhydryl (-SH) was measured as described by Zhang et al. (2018) using a UV-visible spectrophotometer (UVmini-1240, Shimadzu Instruments Co., Ltd., Suzhou, China) [15]. The -SH content was calculated as follows (Equation (3)).

$$
\mathrm{SH}(\mu \mathrm{mol} / \mathrm{g})=\frac{73.53 \times \mathrm{A} \times \mathrm{D}}{\mathrm{C}}
$$

where $\mathrm{A}$ is the absorbance at $412 \mathrm{~nm}, \mathrm{C}$ represents the concentration of freeze-dried dough in $\mathrm{mg} / \mathrm{mL}$, and $\mathrm{D}$ is the dilution factor of supernatant.

\subsection{Cooking Properties and Texture Analysis of FCNs}

Referred to the AACC 6650 (AACC, 2000), FCNs (30 g/500 mL water) were recooked for $90 \mathrm{~s}$ and rinsed in ice-cold water for $1 \mathrm{~min}$. The cooking loss (CL) was defined as the percentage of dry matter that the noodles lose during cooking. The water absorption (WS), which was expressed as the percentage of water absorbed by noodles during cooking, was calculated as the mass ratio after and before cooking.

The texture profile analysis and tensile tests of recooked FCNs were carried out referring to our previous method [12], and measured within $10 \mathrm{~min}$ after recooking.

\subsection{Organoleptic Evaluation}

The recooked FCNs were evaluated by 30 trained panelists (male: female $=1: 1$ ) from the College of Food Science, Northeast Agricultural University. The samples were cut into $5 \mathrm{~cm}$ pieces and then cooked for $90 \mathrm{~s}$ in boiling water at a ratio of 1:10. Then, the samples were placed on dishes marked with random three-digit numbers and provided to all panelists in random order. Some organoleptic attributes such as appearance, texture, flavor, taste, and overall acceptability of FCNs were assessed. A nine-point hedonic scale ranging from 1 (dislike extremely) to 9 (like extremely) was used [19].

\subsection{Statistical Analysis}

All determinations were performed at least in triplicates. The data were expressed as the mean \pm standard deviation (SD) and were examined by one-way analysis of variant (ANOVA) using SPSS (Version 13.0 for Windows, SPSS Inc., Chicago, IL, USA). Differences were considered to be significant at $p<0.05$.

\section{Results}

\subsection{Rheological Properties Analysis}

\subsubsection{Dynamic Frequency Sweep}

As depicted in Figure $1 \mathrm{~A}, \mathrm{~B}$, the $\mathrm{G}^{\prime}$ and $\mathrm{G}^{\prime \prime}$ of the dough containing $\mathrm{NaCl}$ or kansui were higher than those of the control, indicating the degree of gluten cross-linking and the hydration capacity of the dough was enhanced [20]. From Figure 1C, the tan $\delta$ was less than 1 for all dough samples, suggesting that the elastic behavior dominated over the viscous component in the entire frequency range investigated. The tan $\delta$ of the doughs containing $1 \%$ kansui was lower than that of others obviously, indicating that the elastic properties of the dough and the polymerization of gluten proteins were dramatically enhanced [21]. 
Moreover, the tan $\delta$ of the dough containing 3\% $\mathrm{NaCl}$ was higher than that of the dough containing $1 \%$ and $2 \% \mathrm{NaCl}$ significantly, which might be due to the higher levels of $\mathrm{NaCl}$ induced conformational changes and enhanced hydrogen bonding between the gluten components. The viscous flow of glutenin molecules relative to each other with gliadin as the molecular bearing during small strain measurements was conferred, resulting in a higher $\tan \delta$ and a more viscoelastic network [22].

As listed in Table 1, the Power-law model is well fitted to the rheological property curves of each sample, with the corresponding coefficients of determination $\left(R^{2}\right)$ ranging from 0.952 to 0.995 . The $z^{\prime}$ values of all samples ranged from 0.244 to 0.261 , indicating that the gluten network structure was not stable and the covalent bond structure had a certain tendency of physical interaction [15]. Furthermore, the control dough had the lowest K value $\left(0.992 \times 10^{5}\right)$, which demonstrated the lower strength of wheat dough [23]. Dough with $1 \%$ kansui had the highest $\mathrm{K}$ value $\left(2.118 \times 10^{5}\right)$, followed by that of the $1.5 \%$ kansui, $2 \% \mathrm{NaCl}$, and $0.5 \%$ kansui addition. This demonstrated that the addition of kansui to the dough could enhance gluten strength and noodle texture markedly, especially for doughs with $1 \%$ kansui.

\subsubsection{Creep and Recovery Measurements}

Figure 1D exhibited the plots of strain as a function of time for dough samples. The addition of $\mathrm{NaCl} /$ kansui decreased the $\mathrm{J}_{\max }$ of the dough significantly $(p<0.05)$ (Table 1 ), suggesting that $\mathrm{NaCl} /$ kansui enhanced the deformation resistance and rigidity of the dough, especially at $1 \%$ kansui addition [15]. The $\eta_{0}$ showed a similar trend with a reduction of at least $27.82 \%$ and $52.69 \%$, respectively. During the creep phase, $\eta_{0}$ indicated the flowability of dough, which suggested that the addition of $\mathrm{NaCl}$ or kansui made the dough less fluid at the end of the applied load, the dough was less soluble in the solvent and was more stable to maintain a better-processed shape [24]. With increasing $\mathrm{NaCl}$, the minimum value of $\eta_{0}\left(8.74 \times 10^{9} \mathrm{~Pa} \cdot \mathrm{s}\right)$ was achieved for doughs containing $2 \%$ $\mathrm{NaCl}$, showing that this dough had a stronger structure and was more conducive to their subsequent recovery.

In the recovery phase, supplementation of $\mathrm{NaCl}$ or kansui induced higher $\mathrm{J}_{\mathrm{e}} / \mathrm{J}_{\max }$ and lower $\mathrm{J}_{\mathrm{V}} / \mathrm{J}_{\max }$, which suggested a higher dough recovery rate and the formation of a denser cross-linked gluten network. The dough containing 1\% kansui exhibited the maximum $\mathrm{J}_{\mathrm{e}} / \mathrm{J}_{\max }(78.27 \%)$ and the maximum $\mathrm{J}_{\mathrm{V}} / \mathrm{J}_{\max }(21.73 \%)$, which further confirmed that this group presented a more desirable network structure and greater stability against dough film rupture [25].

Table 1. The key parameters of the power law model and creep recovery curve of frozen dough with $\mathrm{NaCl}$ or kansui.

\begin{tabular}{|c|c|c|c|c|c|c|c|}
\hline \multirow[b]{2}{*}{ Samples } & \multirow[b]{2}{*}{$\mathbf{z}^{\prime}$} & \multirow[b]{2}{*}{$\mathrm{K} \times 10^{5}$} & \multirow[b]{2}{*}{$\mathbf{R}^{2}$} & \multicolumn{2}{|c|}{ Creep Phase } & \multicolumn{2}{|c|}{ Recovery Phase } \\
\hline & & & & $\begin{array}{c}\mathrm{J}_{\max } \times 10^{-4} \\
(1 / \mathrm{Pa})\end{array}$ & $\eta_{0} \times 10^{9}(\mathrm{~Pa} \cdot \mathrm{s})$ & $\mathrm{J}_{\mathrm{e}} / \mathrm{J}_{\max }(\%)$ & $\mathrm{J}_{\mathrm{v}} / \mathrm{J}_{\max }(\%)$ \\
\hline Control & $0.261 \pm 0.017^{\mathrm{a}}$ & $0.992 \pm 0.037^{\mathrm{e}}$ & $0.952 \pm 0.049$ & $1.24 \pm 0.09^{\mathrm{a}}$ & $15.96 \pm 0.92^{\mathrm{a}}$ & $54.75 \pm 3.68^{d}$ & $45.26 \pm 3.68^{a}$ \\
\hline N-1 & $0.246 \pm 0.052^{\mathrm{a}}$ & $1.055 \pm 0.049 \mathrm{de}$ & $0.995 \pm 0.002$ & $1.09 \pm 0.11^{b c}$ & $11.52 \pm 1.12^{b}$ & $63.15 \pm 2.03^{c}$ & $36.85 \pm 2.03^{b}$ \\
\hline $\mathrm{N}-2$ & $0.246 \pm 0.015^{a}$ & $1.184 \pm 0.062^{b c}$ & $0.968 \pm 0.046$ & $0.97 \pm 0.07^{\mathrm{cd}}$ & $8.74 \pm 0.77^{c}$ & $73.57 \pm 1.34^{b}$ & $26.43 \pm 1.34^{c}$ \\
\hline N-3 & $0.257 \pm 0.007^{a}$ & $1.071 \pm 0.025^{\mathrm{de}}$ & $0.977 \pm 0.001$ & $0.95 \pm 0.05^{\mathrm{d}}$ & $9.33 \pm 0.63^{c}$ & $72.72 \pm 3.06^{b}$ & $27.28 \pm 3.06^{c}$ \\
\hline K-0.5 & $0.254 \pm 0.003^{a}$ & $1.114 \pm 0.073^{\mathrm{cd}}$ & $0.982 \pm 0.010$ & $1.11 \pm 0.04^{\mathrm{b}}$ & $7.55 \pm 0.25^{\mathrm{d}}$ & $65.95 \pm 3.17^{c}$ & $34.05 \pm 3.17^{b}$ \\
\hline $\mathrm{K}-1$ & $0.244 \pm 0.004^{\mathrm{a}}$ & $2.118 \pm 0.031^{\mathrm{a}}$ & $0.993 \pm 0.004$ & $0.77 \pm 0.03^{e}$ & $6.92 \pm 0.35^{\mathrm{d}}$ & $78.27 \pm 1.22^{\mathrm{a}}$ & $21.73 \pm 1.22^{\mathrm{d}}$ \\
\hline $\mathrm{K}-1.5$ & $0.251 \pm 0.006^{\mathrm{a}}$ & $1.254 \pm 0.077^{b}$ & $0.980 \pm 0.009$ & $0.93 \pm 0.09 \mathrm{~d}$ & $7.34 \pm 0.50^{d}$ & $74.23 \pm 0.72^{b}$ & $25.77 \pm 0.72^{c}$ \\
\hline
\end{tabular}

$\mathrm{z}^{\prime}$, the degree of dependence of $\mathrm{G}^{\prime}$ on frequency sweep. K, the strength of molecular interactions. $R^{2}$, the corresponding coefficients of determination. $J_{\max }$, maximum creep compliance. $\eta_{0}$, the zero-shear viscosity. $\mathrm{J}_{\mathrm{e}} / \mathrm{J}_{\max }$, the relative elastic part of maximum creep compliance. $\mathrm{J}_{\mathrm{v}} / \mathrm{J}_{\max }$, the relative viscous part of maximum creep compliance. Different superscripts in the same column indicate significant difference $(p<0.05)$. 
(A)

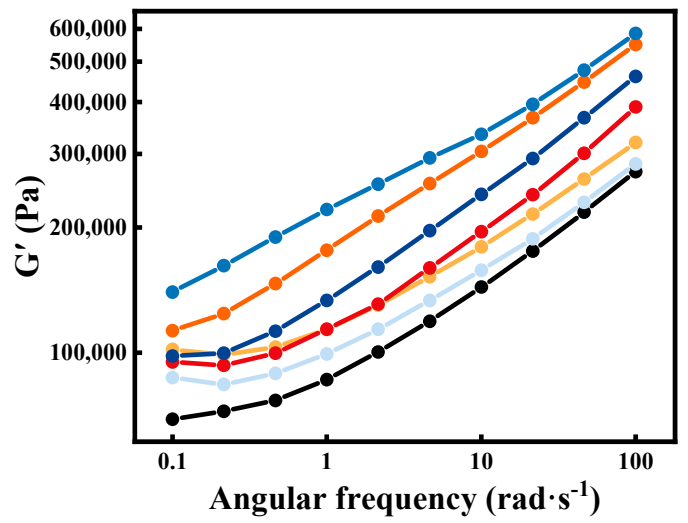

(C)

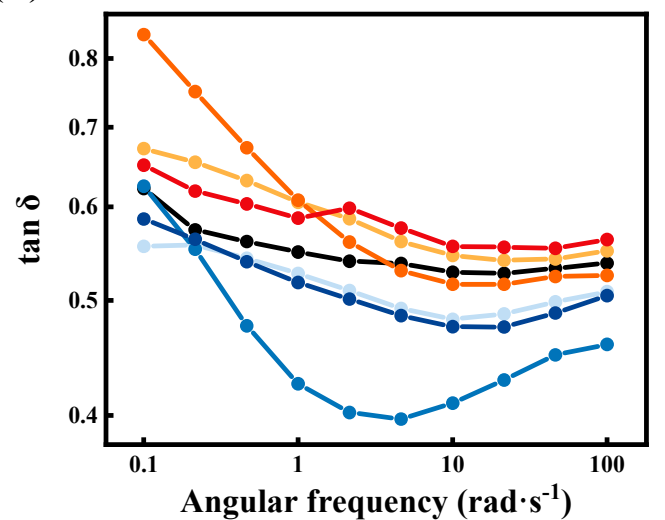

(B)

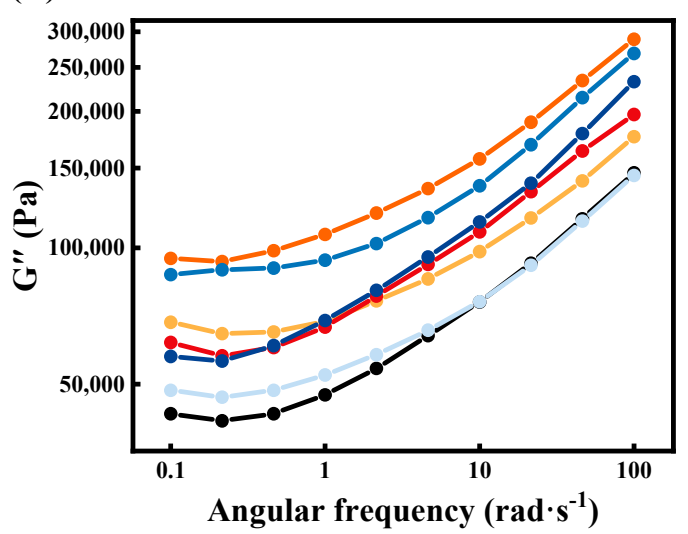

(D)

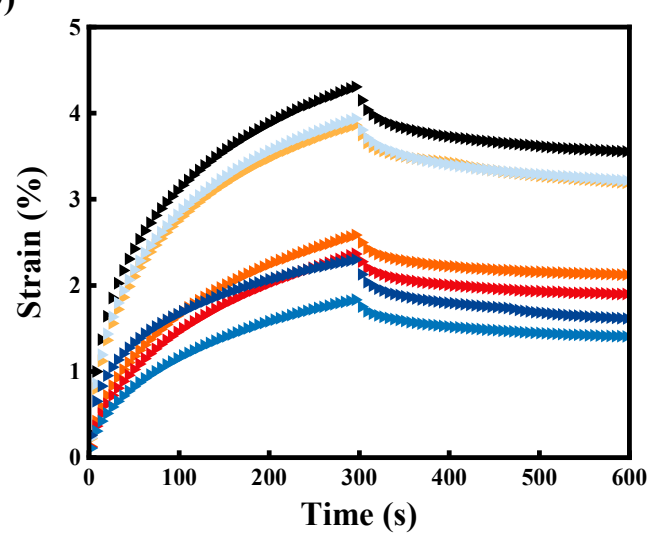

Figure 1. Mechanical spectra and creep-recovery curves of frozen dough. (A) $G^{\prime},(B) G^{\prime \prime}$, and (C) tan $\delta$ versus frequency.

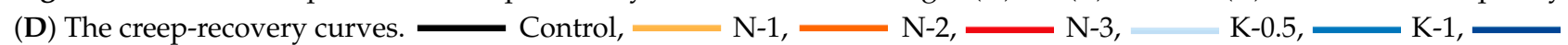
K-1.5.

\subsection{Morphological Characteristics}

As revealed in Figure 2, many voids were observed for the control, which might be related to the sublimation of the ice crystals forming voids in the noodles, while a looser gluten network also caused starch granules to fall off, thus creating voids $[25,26]$. With the addition of $\mathrm{NaCl}$ and kansui, more starch granules were embedded well in the cross-section and the gluten network was more continuous, suggesting that the strengthened gluten network could capture the starch firmly. As $\mathrm{NaCl}$ levels increased from $1 \%$ to $2 \%$, the gluten network changed from less-connected protein particles to an elongated fibrous protein network with stronger adhesion of starch granules. When $\mathrm{NaCl}$ was added over $2 \%$, a few loosely rounded starch granules surrounded by a less dense protein network was observed. This might be explained by the fact that at low levels $(<2 \%), \mathrm{NaCl}$ shielded the charges of the gluten protein, which promoted the slow hydration of the flour and created a more orderly network. Nevertheless, at high levels of $\mathrm{NaCl}(>2 \%)$, excessive shielding and repulsion occurred, with the $\mathrm{NaCl}$ preferring to bind to water, a fact that is detrimental to the hydration of gluten proteins $[8,13]$. 


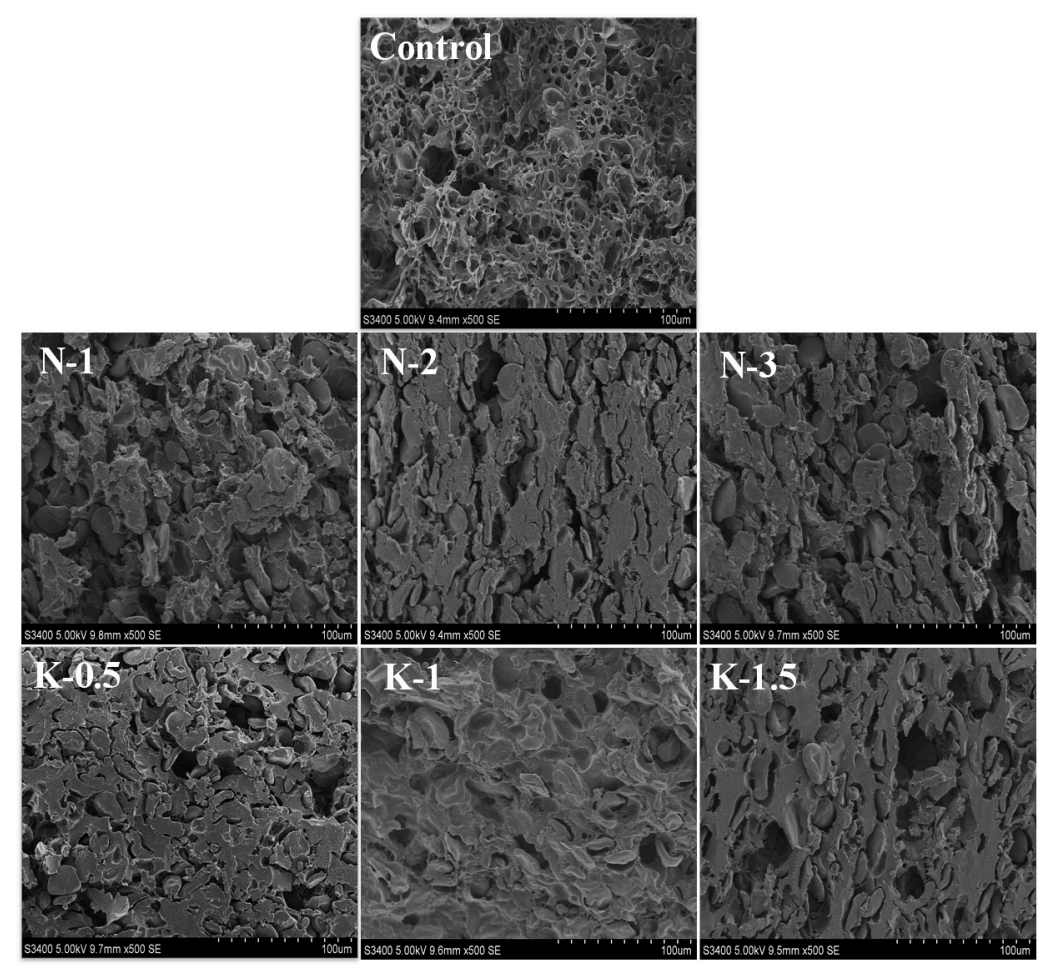

Figure 2. Microscopic morphology of lyophilized frozen cooked noodles.

Similar phenomena were observed in kansui treatment group, with kansui increasing, the number of pores decreased and induced denser membrane-like gluten protein structures. Especially with $1 \%$ kansui level, the starch granules were embedded better in the continuous protein network than other samples. However, excessive kansui resulted in deformed membrane-like gluten network structures with surface swollen starch granules that were not properly embedded in the protein network and could leach into the water during cooking, deteriorating the cooking quality of FCNs. Meanwhile, the porous structure of the unembedded starch granules might also produce more solids loss when the kansui was insufficient [4].

\subsection{Freezable Water Content}

As illustrated in Figure $3 \mathrm{~A}-\mathrm{C}$, both $\mathrm{NaCl}$ or kansui led to a significant decrease of $\Delta \mathrm{H}$ and FW content of FCNs $(p<0.05)$. This indicated that the ice crystallization ability and the number of ice crystals in $\mathrm{FCNs}$ decreased and the addition of $\mathrm{NaCl} /$ kansui could effectively inhibit the progressive liberation of water from the gluten network and ice recrystallization in the dough. These results might be related to the existence of noncovalent interactions between ionic compounds and water, which improved hydration capacity of the dough [27]. Furthermore, the appropriate concentration of $\mathrm{NaCl} /$ kansui could reduce the water migration of frozen dough by inducing a denser gluten structure, thus reducing the number and volume of crystals. The minimum values of $\Delta \mathrm{H}$ (131.77) and FW (57.53\%) were achieved at the $1 \%$ kansui level, indicating greatly enhanced water holding capacity of alkaline noodles. The probable reason was that $\mathrm{NaCl}$ prompted a slight depolymerization of proteins during cooking, while kansui contributed to protein aggregation [11,28], thereby forming a higher spatial barrier. This might also be related to the kansui contributing to an increase of the hydrophilic phase viscosity, resulting in less movement of water molecules that could form ice crystals [29]. 
(A)
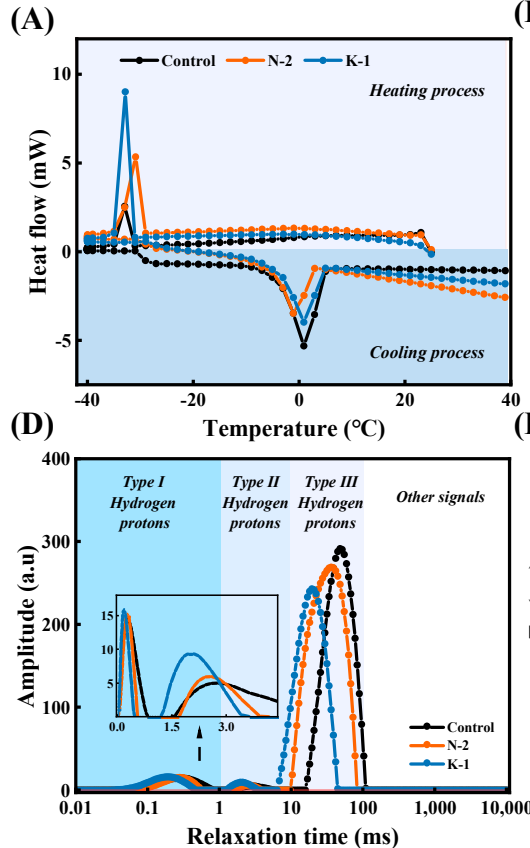

(B)

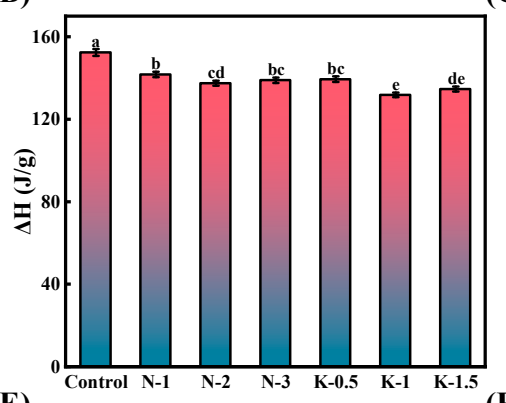

(C)

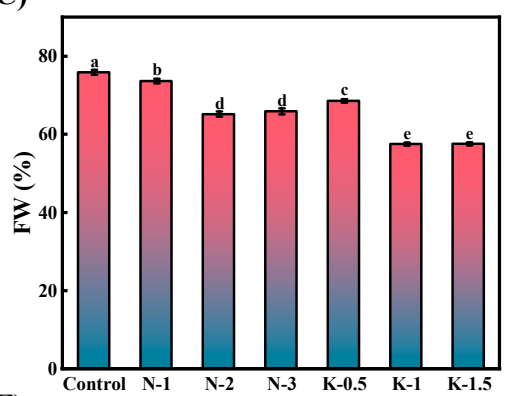

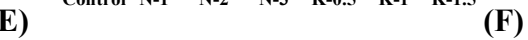
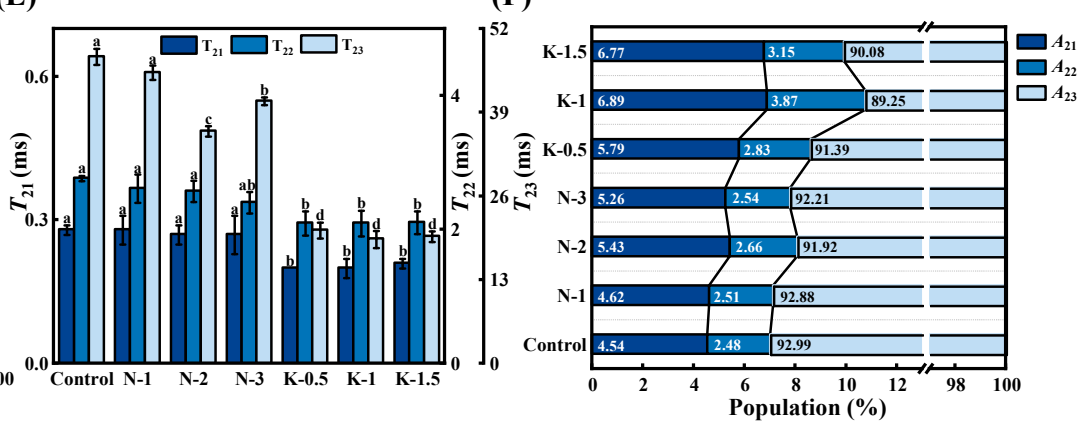

Figure 3. Water distribution of the frozen cooked noodles. (A) Freezing and melting curves. The (B) melting enthalpy $(\Delta \mathrm{H})$ and (C) freezable water content (FW) of frozen cooked noodles. (D) The typical $T_{2}$ relaxation time distribution curve. The (E) relaxation times and (F) peak area proportions of frozen cooked noodles. Different letters in the same bar chart represent significant differences $(p<0.05)$.

\subsection{Water Distribution and Migration \\ 3.4.1. Water Distribution}

The $T_{2}$ spectra as shown in Figure 3D was inverted from the attenuation curve obtained by LF-NMR technology. Three ${ }^{1} \mathrm{H} T_{2}$ populations were observed and named starting from the shorter to the longer relaxation time $T_{21}(0.1-1 \mathrm{~ms}), T_{22}(1-10 \mathrm{~ms})$, and $T_{23}\left(10-100 \mathrm{~ms}\right.$ ), and their proportions were named $A_{21}, A_{22}$, and $A_{23}$, respectively. The relatively short $T_{21}$ represented the tight binding of bound water to non-aqueous components, such as a gluten matrix consisting mainly of protein and starch. The $T_{22}$ composition denoted semi-bound water. In this state, the combination of water molecules with gluten and starch was relatively loose, filling mainly the space of the parallel sheet in gluten. The comparatively long $T_{23}$ was designated as free water, which was mainly distributed in the gluten network voids and was the most mobile [30].

The addition of $\mathrm{NaCl} /$ kansui reduced the $T_{23}$ values of FCNs significantly $(p<0.05)$, indicating that the interaction between water and non-aqueous components was enhanced and the compatibility was improved. Interestingly, the peak apexes of the three populations were shifted to the left distinctly by adding kansui, with $T_{21}$ and $T_{22}$ also decreased from $0.28 \mathrm{~ms}$ and $2.77 \mathrm{~ms}$ to $0.21 \mathrm{~ms}$ and $2.11 \mathrm{~ms}$, respectively, indicating that kansui not only induced greater binding effects between aqueous and non-aqueous components, but also encouraged the dough to exhibit stronger spatial hindrance to delay deeply absorbed water desorbing (as shown in Figure 3E,F). These findings were further confirmed by the $A_{21}$ $(4.54-6.77 \%)$ and $A_{22}(2.48-3.15 \%)$ increased significantly and the $A_{23}(92.99-90.08 \%)$ of the alkaline noodles decreased correspondingly $(p<0.05)$.

With increasing levels of kansui, the relaxation time showed insignificant changes, while the FCNs containing $1 \%$ kansui achieved maximum values of $A_{21}(6.89 \%)$ and $A_{22}$ $(3.87 \%)$ as well as the minimum values of $A_{23}(89.25 \%)$. The sharp drop in free water content of alkaline noodles meant that kansui could reduce the loss of bound water in the dough system more effectively. This might be related to the proper levels of kansui could induce protein polymerization through disulfide bonds or hydrophobic interactions, and form a more compact network structure [9]. Moreover, the appropriate levels of kansui 
helped to maintain the stability of starch granules, which prevented them from being exposed to hydrophobic groups due to damage, thereby contributing to the high hydration capacity of starch during freezing [12].

With increasing $\mathrm{NaCl}$, the minimum values of $T_{23}(36.12 \mathrm{~ms})$ and $A_{23}(91.92 \%)$ related to free water were both obtained at $2 \% \mathrm{NaCl}$ level. $\mathrm{Na}^{+}$ions could prevent starch retrogradation during aging, making starches less likely to build up and loosen, and prompting faster water migration through noodles. However, due to the formation of the protein network, the fewer pores on the surface of $\mathrm{FCNs}$ with $\mathrm{NaCl}$, which decreased the channels for water to penetrate into the noodle [8]. Therefore, $2 \% \mathrm{NaCl}$ induced the formation of a denser gluten network, and the effect of protein network formation on the water migration speed was much greater than the effect of reduced starch lumps size. Overall, water migration could be limited by the addition of appropriate levels of $\mathrm{NaCl} / \mathrm{kansui}$, which was consistent with the DSC results.

\subsubsection{Water Migration}

As illustrated in Figure 4, the addition of $\mathrm{NaCl}$ and kansui could induce lower water mobility and excellent water retention in $\mathrm{FCNs}$. As $\mathrm{NaCl}$ and kansui were increasing, the red areas occupied most of the cross section gradually and the green areas were distributed evenly, indicating that the addition of $\mathrm{NaCl}$ and kansui had an inhibitory effect on water migration and dehydration. Especially for the $2 \% \mathrm{NaCl}$ and $1 \%$ kansui groups, a well-integrated circle of high hydration might be noticed on the outside and the water penetrated gradually from the surface to the interior of the cooked noodles. This suggested that suitable additions of $\mathrm{NaCl}$ and kansui could promote the formation of a coherent gluten network [31]. The red area of Figure 4 (K-1) appeared to be higher than that of (N-2), showing that $1 \%$ kansui provided the dough with the best water retention performance. Furthermore, alkaline noodles exhibited a large difference in water content between the surface and the center, with a higher moisture gradient, which could contribute to a firm texture of FCNs.

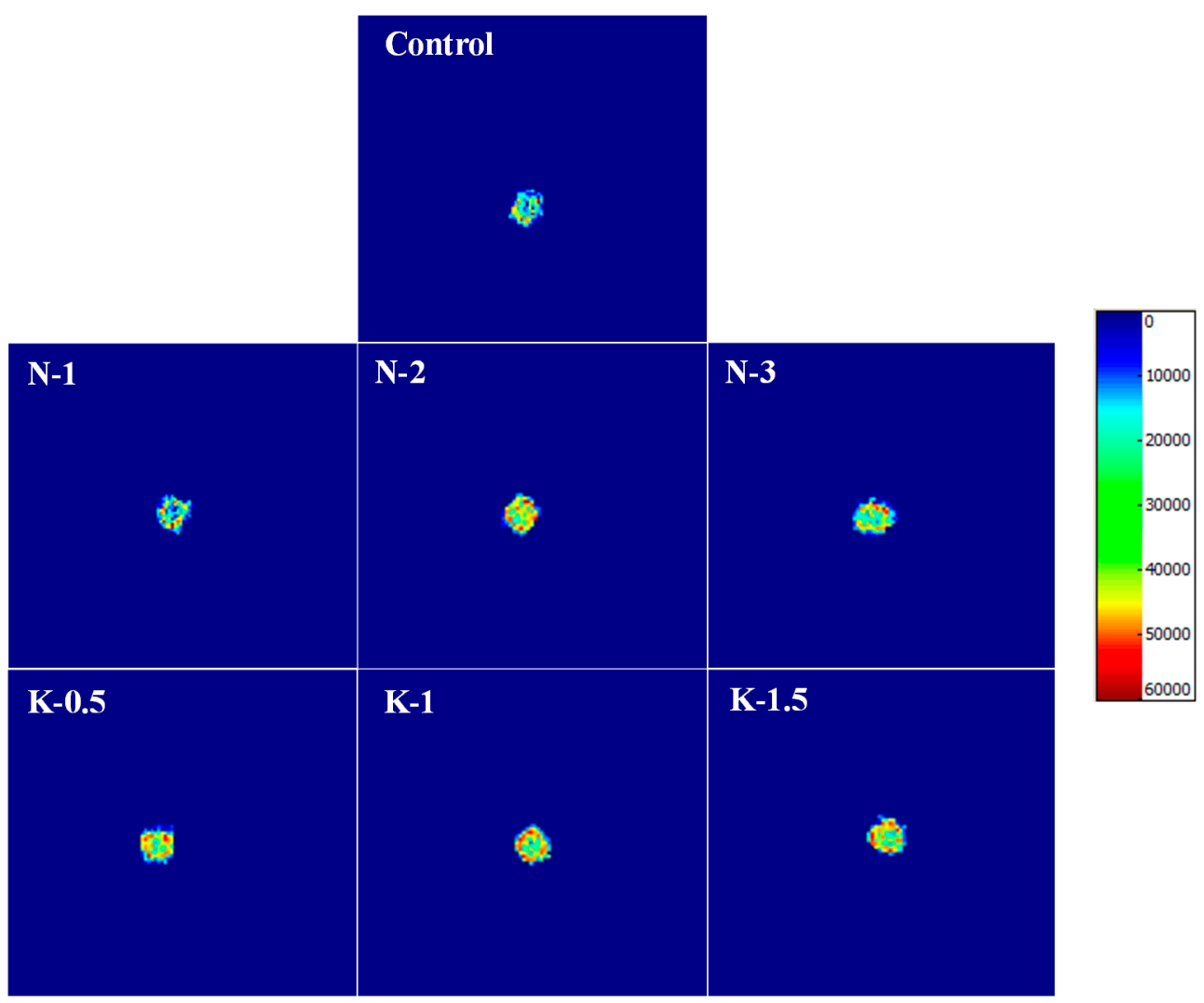

Figure 4. MRI images of the frozen cooked noodles. 


\subsection{Gluten Secondary Structure}

As described in Figure $5 \mathrm{~A}$, both $\mathrm{NaCl}$ and kansui added to the dough caused a significant increase in $\beta$-sheets and $\beta$-turns, while $\alpha$-helixes and random coils decreased significantly $(p<0.05)$. Generally, $\beta$-sheet is recognized as the most stable secondary structure among all of them, which itself increased molecular rigidity and frozen dough strength [28]. As for $\beta$-turns, Bock and Damodaran (2013) reported that $\beta$-turns were the preferred structure of gluten in the fully hydrated state [32]. Furthermore, consecutive $\beta$-turns could form $\beta$-spirals domains with short $\alpha$-helixes on the flank, and the $\beta$-spirals structures contributed to the viscoelasticity of dough [33], which was in line with the rheological results (Section 3.3). Lower contents of $\alpha$-helixes, indicating a change in the order of hydrogen bond and a redistribution of water in frozen doughs. The random coil was typically regarded as a disordered secondary structure, and its reduction suggested that the addition of $\mathrm{NaCl} /$ kansui contributed to the orderliness of protein secondary structure.

(A)
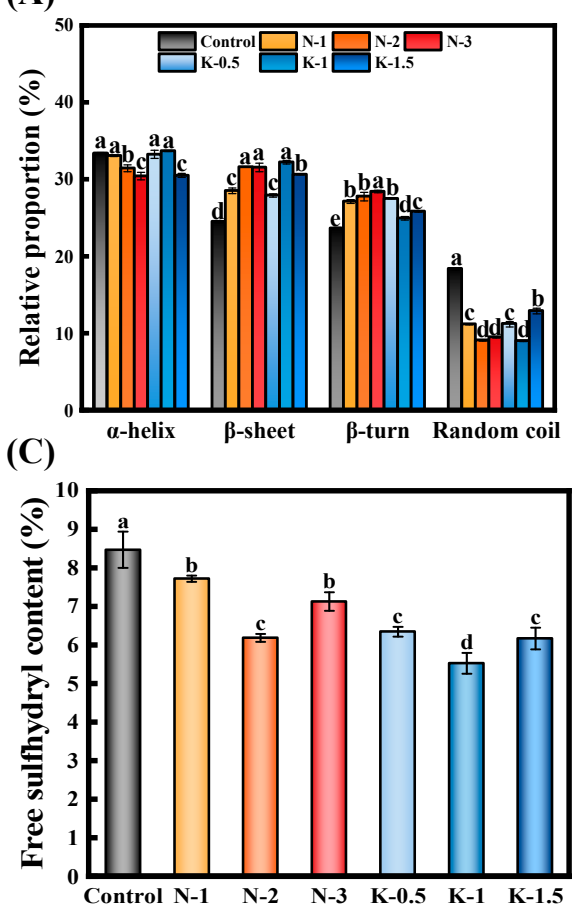

(B)

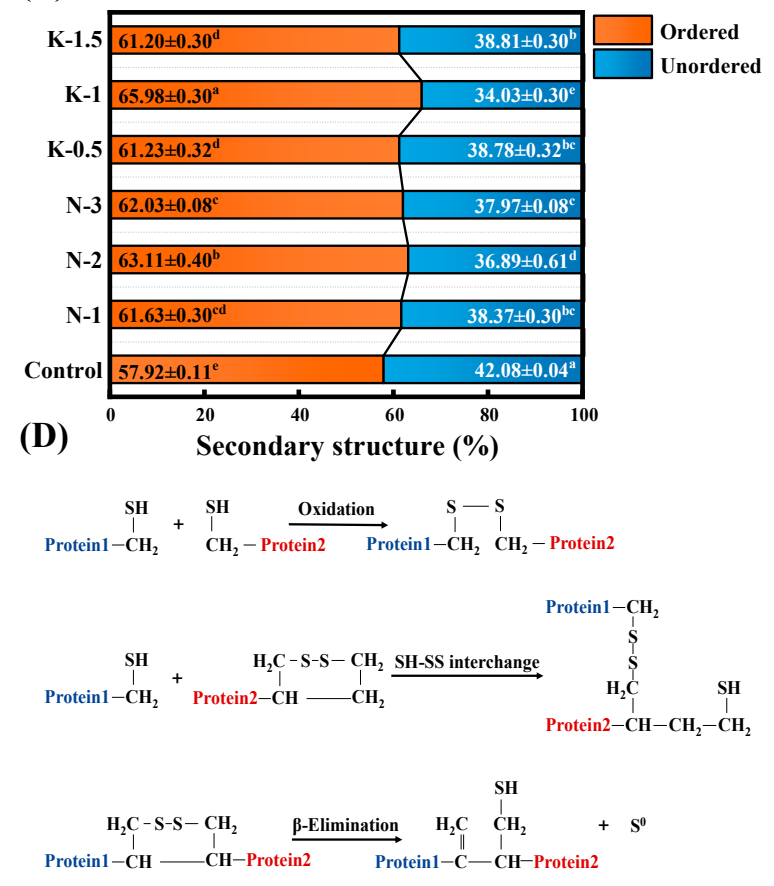

Figure 5. Structural properties of gluten protein. (A) Relative proportion of secondary structure. (B) Breakdown of ordered and unordered structures in gluten protein. (C) The free sulfhydryl content of frozen dough. (D) Overview of some common reactions in or between amino acid chains which are enhanced by alkaline conditions. Different letters in the same bar chart represent significant differences $(p<0.05)$.

Figure 5B displayed the changes in the ordered and unordered portions of the protein. The ordered structure consisted of the $\beta$-sheets and $\alpha$-helixes portions of protein, while the unordered structure involved $\beta$-turns and random coils [34]. The control had $57.92 \%$ ordered structure and $42.08 \%$ unordered structure. The addition of $1 \%$ kansui increased the ordered structure of doughs by $12.22 \%$, with a corresponding decrease in the unordered structure by $19.13 \%$. This could mainly be attributed to their higher content of $\alpha$-helixes (33.73\%) and $\beta$-sheets (32.25\%) conformation, which contributed to inducing stronger intramolecular hydrogen bonds and leading to a more compact and stable dough structure [14]. Based on the stable and tough nature of the $\alpha$-helix structure, its increased content also played an important role in improving the hardness of dough [35]. Furthermore, according to Belton et al. (1995), $\beta$-sheets depended on the hydration of glutenin [36]. The higher $\beta$-sheets further confirmed the contribution of kansui to the water retention capacity of gluten in FCNs. These results might suggest that appropriate levels of kansui 
induced greater unfolding and aggregation of polypeptides than $\mathrm{NaCl}$, leading to more order and dense gluten protein network.

\subsection{Changes of Free Sulfhydryl (-SH) Contents}

From Figure 5C, disulfide bonds are essential for maintaining the gluten proteins structure during freezing, and their integrity is reflected in the content of free $-\mathrm{SH}$. The addition of $\mathrm{NaCl}$ or kansui reduced the $-\mathrm{SH}$ content of doughs significantly $(p<0.05)$ compared with the control. With increasing $\mathrm{NaCl}$, the minimum free sulfhydryl content $(6.19 \mu \mathrm{mol} / \mathrm{g})$ of $\mathrm{FCNs}$ was reached at the level of $2 \% \mathrm{NaCl}$. At $1 \%$ and $3 \%$ concentrations of $\mathrm{NaCl}$, the interactions between the gluten proteins are too weak or strong to aggregate in a rigid form, making the reorientation of the sulfhydryl group contacts difficult and the dough had a higher content of $-\mathrm{SH}$. However, $2 \% \mathrm{NaCl}$ caused local fluctuations in the relative orientation of the glutenins, contributing to the sulfhydryl groups contacts and providing for their subsequent cross-linking, which was fundamental to the glutenin network formation [8]. Overall, the -SH content of the frozen dough showed a wavy trend, with a minimum value $(5.53 \mu \mathrm{mol} / \mathrm{g})$ achieved at the $1 \%$ kansui level. Theoretically, the free -SH underwent two chemical changes in wheat gluten with kansui increasing (Figure $5 \mathrm{D})$, (i) oxidation of the free -SH and SH-SS interchange reactions consume part of the free -SH groups and produce SS cross-linking, and (ii) the $\beta$-elimination reaction, which is more likely to occur under high alkali conditions, causes a significant increase in -SH content, which fitted well with our results $[5,12]$.

\subsection{Quality Characteristics}

\subsubsection{Cooking Properties}

As summarized in Table 2, the WS and CL of noodles varied from $132.95 \%$ to $135.28 \%$ and $4.77 \%$ to $4.89 \%$ with increasing $\mathrm{NaCl}$, respectively, which were slightly higher than those of the control (130.73\% and $4.49 \%)$, but these variations were not significant $(p>0.05)$. However, kansui increased the WS and CL of recooked FCNs significantly, and with kansui increasing, the WS (146.35-155.87\%) and CL (5.92-7.88\%) increased significantly $(p<0.05)$. The higher WS induced by kansui was related to their stronger penetration effect, which might lead to a faster water absorption capacity of doughs during mixing and sheeting, thereby developing a stronger gluten network [8]. Moreover, the CL of noodles with $1.5 \%$ kansui approached twice that of the control. This may be because kansui promoted faster heat transfer by raising the boiling point of the cooking water, resulting in more soluble substances (such as some $\alpha$ - and $\gamma$-gliadins) dissolving into the cooking water and thus increasing the solids loss [28].

\subsubsection{Texture Properties}

The $\mathrm{NaCl}$ and kansui played different roles in alleviating the decline in hardness and tensile properties of FCNs (Table 2), $\mathrm{NaCl}$ resulted in superior dough extensibility, such as tensile strength and breaking distance increased by at least $20.62 \%$ and $27.49 \%$, respectively, while kansui increased noodle hardness (52.74-64.00 N) and chewiness (183.35-282.48) more significantly. The maximum values of tensile strength $(90.35 \mathrm{~g})$ and breaking distance $(61.94 \mathrm{~mm})$ were reached at $2 \% \mathrm{NaCl}$ addition, while higher levels resulted in a significant decrease in the tensile properties of the FCNs $(p<0.05)$. This might be due to the appropriate levels $(2 \%)$ of $\mathrm{NaCl}$ could shield the charges on the proteins and contribute to the elongation of the gluten network [20]. However, the lower tensile capacity of FCNs at higher concentrations of $\mathrm{NaCl}$ might be related to the excessive water intake of noodles during the steaming process, yielding noodles with softened and less recoverable texture as more starch granules are swelled.

With increasing kansui levels, the noodle hardness and chewiness, which were related to gluten strength, showed a concentration-dependent upward trend, while no significant differences were observed after the $1 \%$ kansui level $(p>0.05)$. Kansui could form a tighter and more rigid network structure by promoting protein cross-linking, which might limit 
the collapse of starch molecules and increase the dough strength [5]. Notably, the tensile strength (78.79-72.56 g) and breaking distance (52.32-48.56 mm) of the FCNs decreased significantly $(p<0.05)$ as the kansui levels increased from $1 \%$ to $1.5 \%$, which could be explained as the gluten network in alkaline noodles was already too strong or too firm to maintain sufficient springiness to cushion the expansion of the starch granules produced during cooking before the starch granules were fully pasted, resulting in a less tensile capacity of FCNs [28].

Table 2. Quality characteristics of frozen cooked noodles with $\mathrm{NaCl}$ or kansui.

\begin{tabular}{ccccccc}
\hline \multirow{2}{*}{ Samples } & \multicolumn{2}{c}{ Cooking Properties } & \multicolumn{2}{c}{ Textural Properties } \\
\cline { 2 - 7 } & WS (\%) & CL (\%) & Hardness (N) & Chewiness & $\begin{array}{c}\text { Tensile } \\
\text { Strength (g) }\end{array}$ & $\begin{array}{c}\text { Breaking } \\
\text { Distance (mm) }\end{array}$ \\
\hline Control & $130.73 \pm 5.40^{\mathrm{c}}$ & $4.49 \pm 0.16^{\mathrm{c}}$ & $52.74 \pm 3.81^{\mathrm{c}}$ & $183.35 \pm 15.96^{\mathrm{c}}$ & $66.82 \pm 2.64^{\mathrm{e}}$ & $43.03 \pm 5.00^{\mathrm{d}}$ \\
N-1 & $132.95 \pm 3.22^{\mathrm{c}}$ & $4.77 \pm 0.07^{\mathrm{c}}$ & $55.89 \pm 3.57^{\mathrm{c}}$ & $208.70 \pm 11.94^{\mathrm{c}}$ & $80.60 \pm 1.18^{\mathrm{bc}}$ & $57.18 \pm 2.19^{\mathrm{ab}}$ \\
N-2 & $133.37 \pm 2.73^{\mathrm{c}}$ & $4.82 \pm 0.22^{\mathrm{c}}$ & $56.94 \pm 1.59^{\mathrm{c}}$ & $216.81 \pm 19.63^{\mathrm{bc}}$ & $90.35 \pm 2.81^{\mathrm{a}}$ & $61.94 \pm 2.75^{\mathrm{a}}$ \\
N-3 & $135.28 \pm 2.57^{\mathrm{c}}$ & $4.89 \pm 0.36^{\mathrm{c}}$ & $56.14 \pm 2.52^{\mathrm{c}}$ & $211.89 \pm 17.85^{\mathrm{bc}}$ & $82.96 \pm 2.87^{\mathrm{b}}$ & $54.86 \pm 3.03^{\mathrm{b}}$ \\
K-0.5 & $146.35 \pm 1.24^{\mathrm{b}}$ & $5.92 \pm 0.24^{\mathrm{b}}$ & $58.89 \pm 4.26^{\mathrm{bc}}$ & $246.83 \pm 21.87^{\mathrm{b}}$ & $74.88 \pm 1.58^{\mathrm{cd}}$ & $46.45 \pm 1.52^{\mathrm{d}}$ \\
K-1 & $146.42 \pm 1.75^{\mathrm{b}}$ & $6.35 \pm 0.24^{\mathrm{b}}$ & $65.55 \pm 3.83^{\mathrm{a}}$ & $296.04 \pm 28.52^{\mathrm{a}}$ & $78.79 \pm 6.13^{\mathrm{bcd}}$ & $52.32 \pm 3.91^{\mathrm{bc}}$ \\
K-1.5 & $155.87 \pm 5.36^{\mathrm{a}}$ & $7.88 \pm 0.09^{\mathrm{a}}$ & $64.00 \pm 3.62^{\mathrm{ab}}$ & $282.48 \pm 23.47^{\mathrm{a}}$ & $72.56 \pm 4.89^{\mathrm{de}}$ & $48.56 \pm 2.37^{\mathrm{cd}}$ \\
\hline
\end{tabular}

WS, water absorption. CL, cooking loss. Different superscripts in the same column indicate significant difference $(p<0.05)$.

\subsection{Organoleptic Properties}

As shown in Figure 6, as the levels of $\mathrm{NaCl}$ and kansui increased, the improvement effect on the organoleptic properties of noodles became more significant. In particular, noodles with $1 \%$ kansui had the best sensory scores in terms of appearance, taste, flavor, texture, and overall acceptability, indicating that consumers preferred noodles with a firm texture and high chewiness. The cooked noodles with kansui in the formulation had enhanced aroma compared to the $\mathrm{NaCl}$, indicating that kansui could impart a more desirable flavor to FCNs. This might be related to the fact that kansui could inhibit the formation of non-aroma flavor compounds caused by fat oxidation by adjusting the $\mathrm{pH}$ of the dough [37]. Moreover, the addition of $2 \% \mathrm{NaCl}$ improved the appearance, taste, texture, and overall acceptability of the noodles markedly, which could be explained by the appropriate levels of $\mathrm{NaCl}$ induced the superiority in dough extensibility and recovery ability.

\section{Overall acceptability}

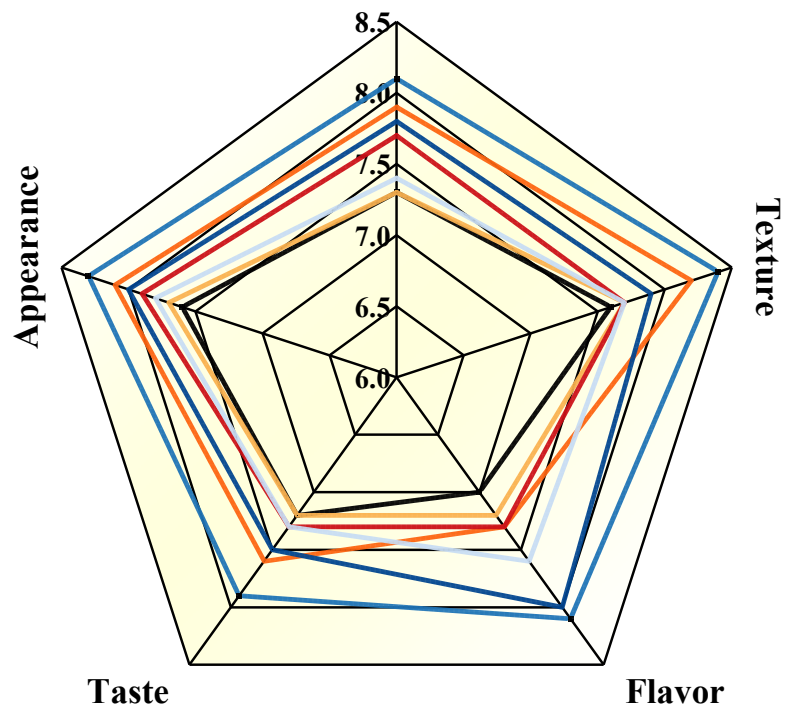

Figure 6. Organoleptic evaluation parameters of frozen cooked noodles. Control, $\mathrm{N}-1, \longrightarrow \mathrm{N}-2, \longrightarrow \mathrm{N}-3, \longrightarrow \mathrm{K}-0.5, \longrightarrow \mathrm{K}-1,-1.5$. 


\subsection{Network Reinforcement Mechanism by $\mathrm{NaCl}$ and Kansui after Freezing}

A model to explain the mechanism whereby $\mathrm{NaCl}$ and kansui affect gluten proteins network formation after freezing was proposed in Figure 7. Previous studies confirmed that frozen storage mainly led to the disaggregation of protein aggregates by destroying the disulfide cross-links between gluten proteins [38]. In our study, $1 \%$ kansui induced more stable intermolecular disulfide bonding in the dough during freezing, which contributed to the more complete gluten structure and stronger water retention capacity of FCNs. Kansui could induce stronger hydrophobic interactions between gluten proteins compared to $\mathrm{NaCl}$ has also been confirmed [9]. In summary, $\mathrm{NaCl}$ and kansui exerted different effects on the stability of the gluten network structure of FCNs after freezing. Kansui stimulated the conversion of free sulfhydryl groups to disulfide bonds obviously, generating denser crosslinks based on the original network. Thus, a greater mechanical force was required to break the alkaline dough. In contrast, $\mathrm{NaCl}$ tended to enhance the original gluten network structure, but contributed to the extensibility of the frozen dough, which could also explain the difference in quality of the recooked FCNs.

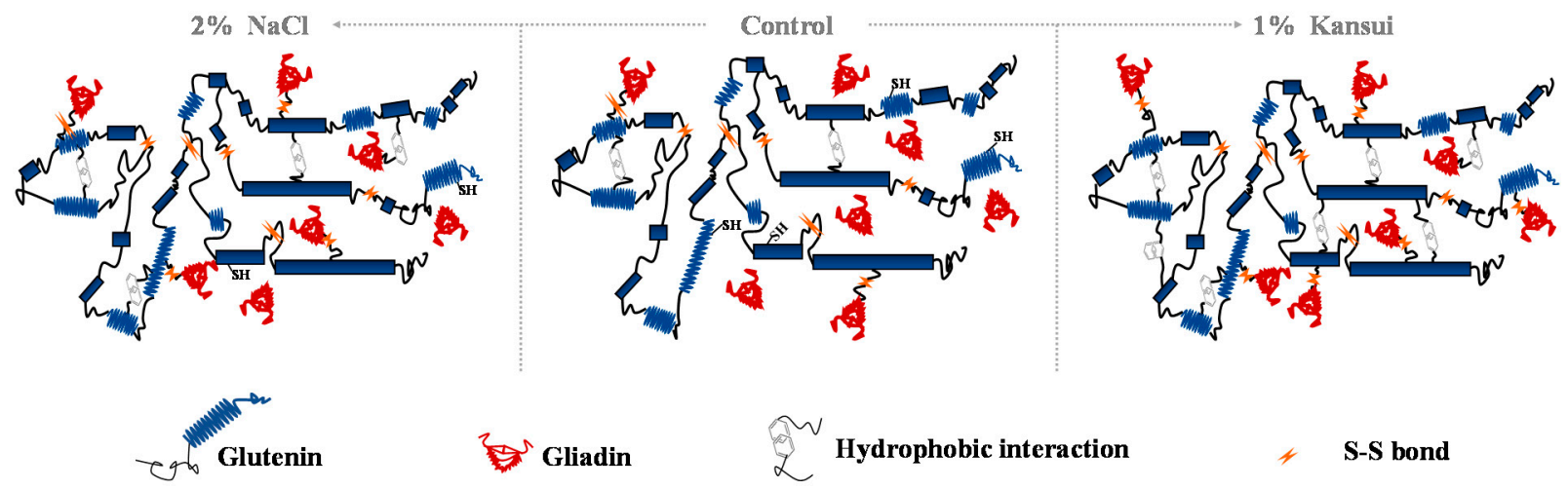

Figure 7. The proposed mechanism for $\mathrm{NaCl}$ and kansui to reinforce the gluten networks in frozen dough.

\section{Conclusions}

There is no doubt that the quality of frozen cooked noodles with $\mathrm{NaCl}$ or kansui showed a significant difference, as explained by the variation in rheological behavior, microscopic morphology, water distribution, and protein structure of dough. Both the addition of $\mathrm{NaCl}$ and kansui to the dough formulation improved the organoleptic properties of FCNs. $\mathrm{NaCl}$ increased the tensile strength and breaking distance of FCNs by at least $20.62 \%$ and $27.49 \%$, respectively; the $2 \% \mathrm{NaCl}$ level especially had the best tensile properties of FCNs, which corresponded to the more elongated fibrous protein network. $\mathrm{NaCl}$ had no significant effect on the cooking quality of frozen cooked noodles. However, kansui increased the water absorption of recooked FCNs significantly $(p<0.05)$, corresponding to the lower freezable water content and higher binding capacity for deeply adsorbed water. The maximum hardness $(65.55 \mathrm{~N})$ and chewiness (296.04) were reached at $1 \%$ kansui levels, which was consistent with the denser membrane-like protein structures, the strongest intermolecular disulfide bonds and the highest protein ordered secondary structure. Rheological results further confirmed that the resistance to deformation and recovery ability of thawed dough were improved significantly at $1 \%$ kansui level. The experimental results obtained in this study may give the noodles industry more fundamental insight into the effect of $\mathrm{NaCl}$ or kansui on the quality attributes of frozen cooked noodles.

Author Contributions: J.W. and J.C. conceived and designed the experiments and reviewed and edited the manuscript; J.W., Y.D., M.W., T.C. and Z.P. contributed materials, analytical tools and participated in the experiments; J.W. analyzed the data; and J.W. and J.C. wrote the manuscript. All authors have read and agreed to the published version of the manuscript. 
Funding: The authors thank the financial support received from the Major Science and Technology Projects in Heilongjiang Province (Project No. 2021ZX12B06).

Conflicts of Interest: The authors have declared no conflict of interest.

\section{References}

1. Obadi, M.; Zhang, J.; Shi, Y.; Xu, B. Factors affecting frozen cooked noodle quality: A review. Trends Food Sci. Technol. 2021, 109, 662-673. [CrossRef]

2. Zhu, F. Frozen steamed breads and boiled noodles: Quality affected by ingredients and processing. Food Chem. 2021, 349, 129178. [CrossRef]

3. Xie, L.; Nishijima, N.; Oda, Y.; Handa, A.; Zhang, Y. Utilization of egg white solids to improve the texture and cooking quality of cooked and frozen pasta. LWT-Food Sci. Technol. 2020, 122, 109031. [CrossRef]

4. Liu, Q.; Guo, X.N.; Zhu, K.X. Effects of frozen storage on the quality characteristics of frozen cooked noodles. Food Chem. 2019, 283, 522-529. [CrossRef]

5. Jia, F.; Ma, Z.; Wang, X.; Li, X.; Liu, L.; Hu, X.J. Effect of kansui addition on dough rheology and quality characteristics of chickpea-wheat composite flour-based noodles and the underlying mechanism. Food Chem. 2019, 298, 125081. [CrossRef] [PubMed]

6. Fu, B.X. Asian noodles: History, classification, raw materials, and processing. Food Res. Int. 2008, 41, 888-902. [CrossRef]

7. He, H.; Roach, R.R.; Hoseney, R.C. Effect of nonchaotropic salts on flour bread-making properties. Cereal Chem. 1992, 69, 366-371.

8. Fan, H.P.; Fu, F.; Chen, Y.H.; Liu, M.; Ai, Z.L.; Bian, K. Effect of $\mathrm{NaCl}$ on rheological properties of dough and noodle quality. J. Cereal Sci. 2020, 93, 102936. [CrossRef]

9. Han, C.W.; Ma, M.; Yang, T.B.; Li, M.; Sun, Q.J. Heat mediated physicochemical and structural changes of wheat gluten in the presence of salt and alkali. Food Hydrocoll. 2021, 120, 106971. [CrossRef]

10. Gulia, N.; Dhaka, V.; Khatkar, B.S. Instant Noodles: Processing, Quality, and Nutritional Aspects. Crit. Rev. Food Sci. Nutr. 2014, 54, 1386-1399. [CrossRef]

11. Li, M.; Sun, Q.J.; Han, C.W.; Chen, H.H.; Tang, W.T. Comparative study of the quality characteristics of fresh noodles with regular salt and alkali and the underlying mechanisms. Food Chem. 2017, 246, 335-342. [CrossRef]

12. Ding, Y.Y.; Wang, J.R.; Sun, L.N.; Zhou, X.N.; Cheng, J.J.; Sun, Y.X. Effect of kansui on the physicochemical, structural, and quality characteristics of adlay seed flour-fortified wheat noodles. LWT-Food Sci. Technol. 2021, 146, 111458. [CrossRef]

13. Yeoh, S.Y.; Lubowa, M.; Tan, T.C.; Murad, M.; Easa, A.M. The use of salt-coating to effect textural, mechanical, cooking and sensory properties of air-dried yellow alkaline noodles. Food Chem. 2020, 333, 127425. [CrossRef] [PubMed]

14. Hong, T.; Ma, Y.; Yuan, Y.; Guo, L.; Xu, D.; Wu, F.; Xu, X. Understanding the influence of pullulan on the quality changes, water mobility, structural properties and thermal properties of frozen cooked noodles. Food Chem. 2021, 365, 130512. [CrossRef]

15. Zhang, D.Q.; Mu, T.H.; Sun, H.N. Effects of starch from five different botanical sources on the rheological and structural properties of starch-gluten model doughs. Food Res. Int. 2018, 103, 156-162. [CrossRef] [PubMed]

16. Yang, X.Y.; Ke, C.X.; Li, L. Physicochemical, rheological and digestive characteristics of soy protein isolate gel induced by lactic acid bacteria. J. Food Eng. 2020, 292, 110243. [CrossRef]

17. Wang, Y.H.; Zhang, Y.R.; Xu, F.; Zhang, Y.L. Effect of boiling and steaming on the surface tackiness of frozen cooked noodles. LWT-Food Sci. Technol. 2020, 130, 109747. [CrossRef]

18. Sun, Y.; Wang, M.C.; Ma, S.P.; Wang, H.S. Physicochemical characterization of rice, potato, and pea starches, each with different crystalline pattern, when incorporated with Konjac glucomannan. Food Hydrocoll. 2020, 101, 105499. [CrossRef]

19. Sofi, S.A.; Singh, J.; Chhikara, N.; Panghal, A.; Gat, Y. Quality characterization of gluten free noodles enriched with chickpea protein isolate. Food Biosci. 2020, 36, 100626. [CrossRef]

20. Tan, H.L.; Tan, T.C.; Mat, E.A. Comparative study of cooking quality, microstructure, and textural and sensory properties between fresh wheat noodles prepared using sodium chloride and salt substitutes. LWT-Food Sci. Technol. 2018, 97, 396-403. [CrossRef]

21. Shao, L.F.; Guo, X.N.; Li, M.; Zhu, K.X. Effect of different mixing and kneading process on the quality characteristics of frozen cooked noodle. LWT-Food Sci. Technol. 2018, 101, 583-589. [CrossRef]

22. McCann, T.H.; Day, L. Effect of sodium chloride on gluten network formation, dough microstructure and rheology in relation to breadmaking. J. Cereal Sci. 2013, 57, 444-452. [CrossRef]

23. Cao, Y.; Jiang, L.; Suo, W.; Deng, Y.; Zhang, M.; Dong, S.; Guo, P.; Chen, S.; Li, H. Influence of emulsifiers and enzymes on dough rheological properties and quality characteristics of steamed bread enriched with potato pulp. Food Chem. 2021, 360, 130015. [CrossRef] [PubMed]

24. Feng, Y.Y.; Mu, T.H.; Zhang, M.; Ma, M.M. Effects of ionic polysaccharides and egg white protein complex formulations on dough rheological properties, structure formation and in vitro starch digestibility of wet sweet potato vermicelli. Int. J. Biol. Macromol. 2020, 149, 1170-1179. [CrossRef]

25. Yang, J.; Zhang, B.; Zhang, Y.; Rasheed, M.; Gu, S.; Guo, B. Effect of freezing rate and frozen storage on the rheological properties and protein structure of non-fermented doughs. J. Food Eng. 2021, 293, 110377. [CrossRef]

26. Wang, Y.H.; Zhang, Y.R.; Xu, F.; Li, Z.K. Effects of water addition and noodle thickness on the surface tackiness of frozen cooked noodles. J. Food Process Preserv. 2020, 44, e14717. [CrossRef] 
27. Lu, L.; Yang, Z.; Guo, X.N.; Xing, J.J.; Zhu, K.X. Effect of $\mathrm{NaHCO}_{3}$ and freeze-thaw cycles on frozen dough: From water state, gluten polymerization and microstructure. Food Chem. 2021, 358, 129869. [CrossRef] [PubMed]

28. Rombouts, I.; Jansens, K.; Lagrain, B.; Delcour, J.A.; Zhu, K.X. The impact of salt and alkali on gluten polymerization and quality of fresh wheat noodles. J. Cereal Sci. 2014, 60, 507-513. [CrossRef]

29. Luo, L.J.; Guo, X.N.; Zhu, K.X. Effect of steaming on the quality characteristics of frozen cooked noodles. LWT-Food Sci. Technol. 2015, 62, 1134-1140. [CrossRef]

30. Liang, Y.; Qu, Z.; Liu, M.; Zhu, M.; Wang, J. Further interpretation of the strengthening effect of curdlan on frozen cooked noodles quality during frozen storage: Studies on water state and properties. Food Chem. 2020, 346, 128908. [CrossRef]

31. Liu, L.; Shi, Z.; Wang, X.; Ren, T.; Ma, Z.; Li, X.; Xu, B.; Hu, X. Interpreting the correlation between repeated sheeting process and wheat noodle qualities: From water molecules movement perspective. LWT-Food Sci. Technol. 2021, 151, 112219. [CrossRef]

32. Bock, J.E.; Damodaran, S. Bran-induced changes in water structure and gluten conformation in model gluten dough studied by Fourier transform infrared spectroscopy. Food Hydrocoll. 2013, 31, 146-155. [CrossRef]

33. Xu, X.J.; Luo, Z.G.; Yang, Q.Y.; Xiao, Z.G.; Lu, X.X. Effect of quinoa flour on baking performance, antioxidant properties and digestibility of wheat bread. Food Chem. 2019, 294, 87-95. [CrossRef] [PubMed]

34. Vanga, S.K.; Wang, J.; Orsat, V.; Raghavan, V. Effect of pulsed ultrasound, a green food processing technique, on the secondary structure and in-vitro digestibility of almond milk protein. Food Res. Int. 2020, 137, 109523. [CrossRef]

35. Li, C.; Chen, G.; Ran, C.; Liu, L.; Wang, S.; Xu, Y.; Tan, Y.; Kan, J. Adlay starch-gluten composite gel: Effects of adlay starch on rheological and structural properties of gluten gel to molecular and physico-chemical characteristics. Food Chem. 2019, 289, 121-129. [CrossRef]

36. Belton, P.S.; Colquhoun, I.J.; Grant, A.; Wellner, N.; Field, J.M.; Shewry, P.R.; Tatham, A.S. FTIR and NMR studies on the hydration of a high-Mr subunit of glutenin. Int. J. Biol. Macromol. 1995, 17, 74-80. [CrossRef]

37. $\mathrm{Xi}$, J.; $\mathrm{Xu}, \mathrm{D}$.; $\mathrm{Wu}, \mathrm{F} . ; \mathrm{Jin}, \mathrm{Z}$; $\mathrm{Xu}, \mathrm{X}$. Effect of $\mathrm{Na}_{2} \mathrm{CO}_{3}$ on quality and volatile compounds of steamed bread fermented with yeast or sourdough. Food Chem. 2020, 324, 126786. [CrossRef]

38. Wang, P.; Xu, L.; Nikoo, M.; Ocen, D.; Wu, F.F.; Yang, N.; Jin, Z.Y.; Xu, X.M. Effect of frozen storage on the conformational, thermal and microscopic properties of gluten: Comparative studies on gluten-, glutenin- and gliadin-rich fractions. Food Hydrocoll. 2014, 35, 238-246. [CrossRef] 